\title{
Head Impact Exposure in Youth Football: Elementary School Ages 9-12 Years and the Effect of Practice Structure
}

\author{
Bryan R. Cobb, ${ }^{1}$ Jillian E. Urban, ${ }^{2,3}$ Elizabeth M. Davenport, ${ }^{2,3}$ Steven Rowson, ${ }^{1}$ Stefan M. Duma, ${ }^{1}$ \\ Joseph A. Maldjian, ${ }^{2,4}$ Christopher T. Whitlow, ${ }^{4,5}$ Alexander K. Powers, ${ }^{6,7}$ and Joel D. Stitzel ${ }^{2,7}$ \\ ${ }^{1}$ School of Biomedical Engineering \& Sciences, Virginia Tech-Wake Forest University, 440 ICTAS Building, Stanger St., \\ Blacksburg, VA 24061, USA; ${ }^{2}$ School of Biomedical Engineering \& Sciences, Virginia Tech-Wake Forest University, Medical \\ Center Blvd., Winston-Salem, NC 27157, USA; ${ }^{3}$ Wake Forest School of Medicine, Medical Center Blvd., Winston-Salem, \\ NC 27157, USA; ${ }^{4}$ Department of Radiology (Neuroradiology), Wake Forest School of Medicine, Winston-Salem, NC 27157, \\ USA; ${ }^{5}$ Translational Science Institute, Wake Forest School of Medicine, Winston-Salem, NC 27157, USA; ${ }^{6}$ Department of \\ Neurosurgery, Wake Forest School of Medicine, Winston-Salem, NC 27157, USA; and ${ }^{7}$ Childress Institute for Pediatric
} Trauma, Wake Forest School of Medicine, Winston-Salem, NC 27157, USA

(Received 1 March 2013; accepted 8 July 2013; published online 24 July 2013)

Associate Editor Peter E. McHugh oversaw the review of this article.

\begin{abstract}
Head impact exposure in youth football has not been well-documented, despite children under the age of 14 accounting for $70 \%$ of all football players in the United States. The objective of this study was to quantify the head impact exposure of youth football players, age 9-12, for all practices and games over the course of single season. A total of 50 players (age $=11.0 \pm 1.1$ years) on three teams were equipped with helmet mounted accelerometer arrays, which monitored each impact players sustained during practices and games. During the season, 11,978 impacts were recorded for this age group. Players averaged $240 \pm 147$ impacts for the season with linear and rotational 95th percentile magnitudes of $43 \pm 7 \mathrm{~g}$ and $2034 \pm 361 \mathrm{rad} / \mathrm{s}^{2}$. Overall, practice and game sessions involved similar impact frequencies and magnitudes. One of the three teams however, had substantially fewer impacts per practice and lower 95th percentile magnitudes in practices due to a concerted effort to limit contact in practices. The same team also participated in fewer practices, further reducing the number of impacts each player experienced in practice. Head impact exposures in games showed no statistical difference. While the acceleration magnitudes among 9-12 year old players tended to be lower than those reported for older players, some recorded high magnitude impacts were similar to those seen at the high school and college level. Head impact exposure in youth football may be appreciably reduced by limiting contact in practices. Further research is required to assess whether such a reduction in head impact exposure will result in a reduction in concussion incidence.
\end{abstract}

Address correspondence to Steven Rowson, School of Biomedical Engineering \& Sciences, Virginia Tech-Wake Forest University, 440 ICTAS Building, Stanger St., Blacksburg, VA 24061, USA. Electronic mail: srowson@vt.edu
Keywords-Concussion, Brain injury, Biomechanics, Helmet, Linear, Rotational, Acceleration, Pediatrics, Children, Sports.

\section{INTRODUCTION}

In recent years, football has come under increased scrutiny because of the concern for player safety and the risk of injury, especially related to concussion. Researchers estimate that between 1.6 and 3.8 million cases of sports related concussion occur each year in the United States, with football having the highest rate of injury among team sports. ${ }^{14,19}$ While the long term effects of sports concussions are still under investigation, links may exist between the accumulation of head impacts over a playing career and increased risk of neurodegenerative diseases later in life, among other health concerns. ${ }^{30}$ The majority of the biomechanics research investigating concussions in football has been focused on high school, college, and professional players, despite that more than two-thirds of football players are under the age of $14 .{ }^{11}$

In order to understand the biomechanics associated with concussion, numerous studies have been conducted over the last decade to investigate player exposure and tolerance to head impacts in football. . $^{3,7,7,9,10,13,16,17,22,23,25-27,31-34}$ Many of these studies have utilized commercially available helmet-mounted accelerometer arrays (Head Impact Telemetry (HIT) System, Simbex, Lebanon, NH) to measure head kinematics resulting from head impact in real-time during live play. The accelerometer arrays collect data 
from each head impact a player experiences while instrumented, allowing researchers to get a more complete view of the biomechanical response of a player's head to impacts across a wide range of magnitudes. Since 2003, more than 1.5 million impacts have been recorded using the HIT system, primarily at the high school and college level. ${ }^{7-10,12}$ From these data, strategies to reduce head impact exposure through rule changes and methods to evaluate protective equipment have been developed. ${ }^{8-10,25}$ Unfortunately, little research has focused on youth football, where the head impact exposure is still not well understood. ${ }^{11}$ A single study has investigated head impact exposure at the youth level. That study found that 7 and 8 year old players sustained an average of 107 impacts over the course of a season, with the majority of high magnitude impacts occurring in practice. ${ }^{11}$ This work was one factor contributing to youth football organizations updating contact restrictions during practice. ${ }^{28}$

An estimated 5 million athletes participate in organized football in the United States annually. Children, age 6-13 years, account for around 3.5 million of these participants, compared to just 2000 in the National Football League (NFL), 100,000 in college, and 1.3 million in high school. ${ }^{11,18,24}$ Despite making up $70 \%$ of the football playing population, just one study has investigated head impact exposure experienced by youth football players under 14 years old. The objective of this study was to quantify the head impact exposure of youth football players, aged 9-12 years, for all practices and games over the course of single season. These data, along with future research, may be used in the development of scientifically based strategies for head injury mitigation.

\section{MATERIALS AND METHODS}

On-field head impact data were collected from 50 players, age 9-12 years, on three youth tackle football teams instrumented with the HIT system for a single fall football season. The three teams consisted of a juniors team (team A, 9-11 years old), a pee wee team (team B, 10-12 years old), and a junior pee wee team (team C, 9-11 years old). Further description of the three teams is provided in Table 1. Players were monitored during each of the teams' games and contact practices. Approval for this study was given by the Virginia Tech and Wake Forest University Institutional Review Boards (IRBs). Each player provided assent and their parent/guardian gave written consent for participation in the study.

The HIT system consists of an array of six nonorthogonally mounted single-axis accelerometers oriented normal to the surface of the head. The arrays, designed to fit in medium or large Riddell Revolution helmets, were installed between the existing padding inside the helmets. Each accelerometer is mounted on an elastic base so that they remain in contact with the head throughout the duration of head impact, allowing for the measurement of head acceleration rather than that of the helmet. ${ }^{20}$ Any time an instrumented player experienced a head impact that resulted in a single accelerometer measuring $14.4 \mathrm{~g}$ during games and practices, data acquisition was triggered to record $40 \mathrm{~ms}$ of data at $1000 \mathrm{~Hz}$, including $8 \mathrm{~ms}$ of pre-trigger data. Data from the helmet-mounted accelerometers were then transmitted wirelessly to a computer on the sideline, where the data were stored and processed to compute resultant linear head acceleration and peak rotational head acceleration using previously described methods. ${ }^{6,27}$ In addition, impact location was generalized into 1 of 4 impact locations (front, side, top, or back) based on the acceleration vectors from the linear accelerometers. ${ }^{15}$ Impacts were verified using video from practice and game sessions to ensure they occurred while players were wearing the helmets. The HIT system has previously been found to reliably determine linear acceleration, peak rotational acceleration, and impact location. ${ }^{1}$

Empirical cumulative distribution functions (CDF) for both linear and rotational head acceleration were determined. Head impact exposure was quantified in terms of impact frequency and 50th and 95th percentile head accelerations. Acceleration duration was measured from the local minimum before peak linear acceleration and the local minimum after the peak, while time to peak linear acceleration was measured from the local minimum before peak linear acceleration to the peak. The data were sorted by generalized impact location and session type (practice or game). A Kruskal-Wallis oneway analysis of variance was conducted to evaluate for between-group differences in head impact exposure associated with the three teams and two session types. A threshold of $p<0.05$ was used to determine statistical significance. In the event that more than two groups were compared, $p$ values were calculated for all pairs and the most conservative $p$ value was reported. All data analysis was conducted on an individual player basis and then averaged to represent the exposure level of a typical 912 year old football player. Head impact exposure levels were then compared with those of other levels of play that have been previously described in the literature.

\section{RESULTS}

A total of 11,978 impacts were measured, ranging from linear accelerations of $10-126 \mathrm{~g}$ and rotational accelerations of 4-5838 $\mathrm{rad} / \mathrm{s}^{2}$. The distribution of linear acceleration had a median value of $19 \mathrm{~g}$ and a 95th 
percentile value of $46 \mathrm{~g}$. The distribution of rotational acceleration had a median value of $890 \mathrm{rad} / \mathrm{s}^{2}$ and a $95 \mathrm{th}$ percentile value of $2081 \mathrm{rad} / \mathrm{s}^{2}$. CDFs of linear and rotational acceleration magnitudes for the season were determined (Fig. 1). The acceleration distributions are right-skewed and heavily weighted toward lower magnitude impacts. The impact durations measured were $8.82 \pm 2.97 \mathrm{~ms}$ (average \pm standard deviation) with a time to peak linear acceleration of $4.67 \pm 1.73 \mathrm{~ms}$. Resultant linear acceleration is plotted vs. time for several impacts recorded in this study as, examples of a typical acceleration pulse (Fig. 2).

On average, instrumented players sustained $240 \pm 147$ impacts during the season, with values ranging from 26 to 585 impacts. The average instrumented player sustained $10.6 \pm 5.2$ impacts per session while participating in $21.8 \pm 5.7$ sessions. The median impact sustained by instrumented players resulted in accelerations of $18 \pm 2 \mathrm{~g}$ and $856 \pm 135 \mathrm{rad} / \mathrm{s}^{2}$. The 95th percentile impact sustained by instrumented players resulted in accelerations of $43 \pm 7 \mathrm{~g}$ and $2034 \pm 361 \mathrm{rad} / \mathrm{s}^{2}$. Head impact exposure was quantified on an individual player basis by session type (Table 2). A total of 961 impacts $(8.0 \%)$ greater than $40 \mathrm{~g}, 160$ impacts $(1.3 \%)$ greater than $60 \mathrm{~g}$, and 36 impacts $(0.3 \%)$ greater than $80 \mathrm{~g}$ were recorded throughout the season. The average player sustained $19.2 \pm 20.1$ impacts greater than $40 \mathrm{~g}, 3.2 \pm 4.4 \mathrm{im}-$ pacts greater than $60 \mathrm{~g}$, and $0.7 \pm 1.2$ impacts greater than $80 \mathrm{~g}$.
In games, the average player had a median linear acceleration value of $19 \pm 2 \mathrm{~g}$ and a 95th percentile value of $43 \pm 8 \mathrm{~g}$. The average player had a median linear acceleration value of $18 \pm 2 \mathrm{~g}$ and 95th percentile value of $40 \pm 7 \mathrm{~g}$ in practices. Both the difference in median $(p=0.0289)$ and 95th percentile $(p=0.0463)$ linear acceleration magnitudes between games and practices were significant. For rotational acceleration, the average player had a median value of $867 \pm 149 \mathrm{rad} / \mathrm{s}^{2}$ and a 95th percentile value of $2117 \pm 436 \mathrm{rad} / \mathrm{s}^{2}$ for games. In practices, the average

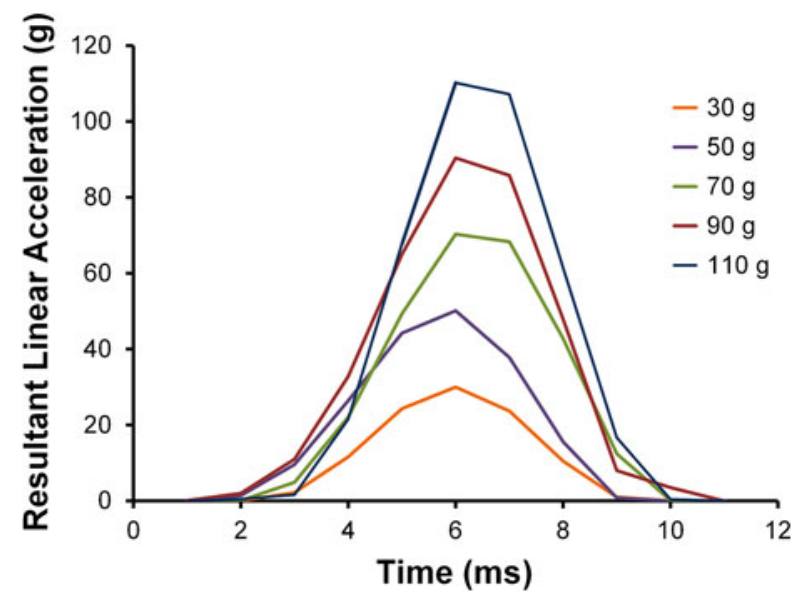

FIGURE 2. Resultant linear acceleration vs. time for several impacts of various magnitudes recorded from 9 to 12 year old football players.

TABLE 1. Description of subject groups investigated in this study.

\begin{tabular}{lccrr}
\hline Team & Player mass $(\mathrm{kg})$ & Player age (years) & Number of players & Number of impacts \\
\hline A & $37.6 \pm 5.7$ & $9.8 \pm 0.8$ & 14 & 2206 \\
B & $50.1 \pm 3.9$ & $12.2 \pm 0.5$ & 17 & 5005 \\
C & $43.9 \pm 5.9$ & $10.9 \pm 0.6$ & 19 & 4767 \\
Combined & $44.2 \pm 7.2$ & $11.0 \pm 1.1$ & 50 & 11,978 \\
\hline
\end{tabular}
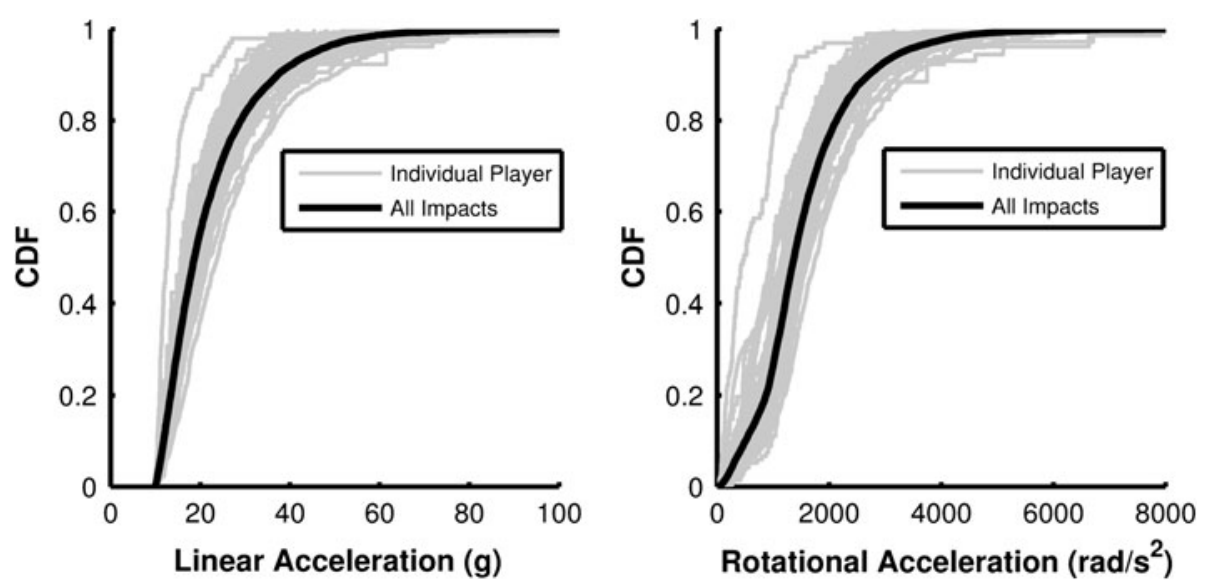

FIGURE 1. Cumulative distribution plots of linear acceleration (left) and rotational acceleration (right) magnitudes for impacts collected during the season. 


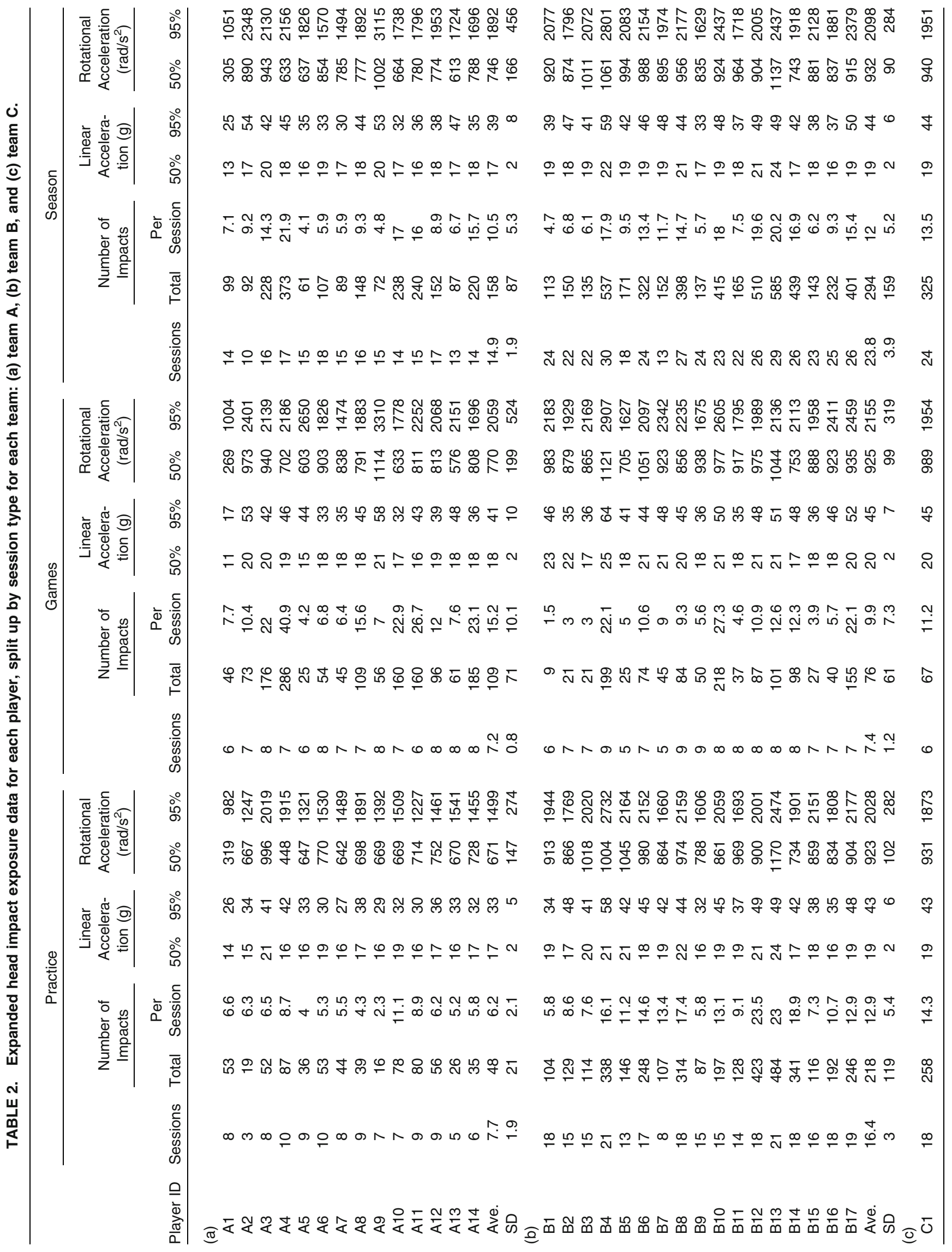




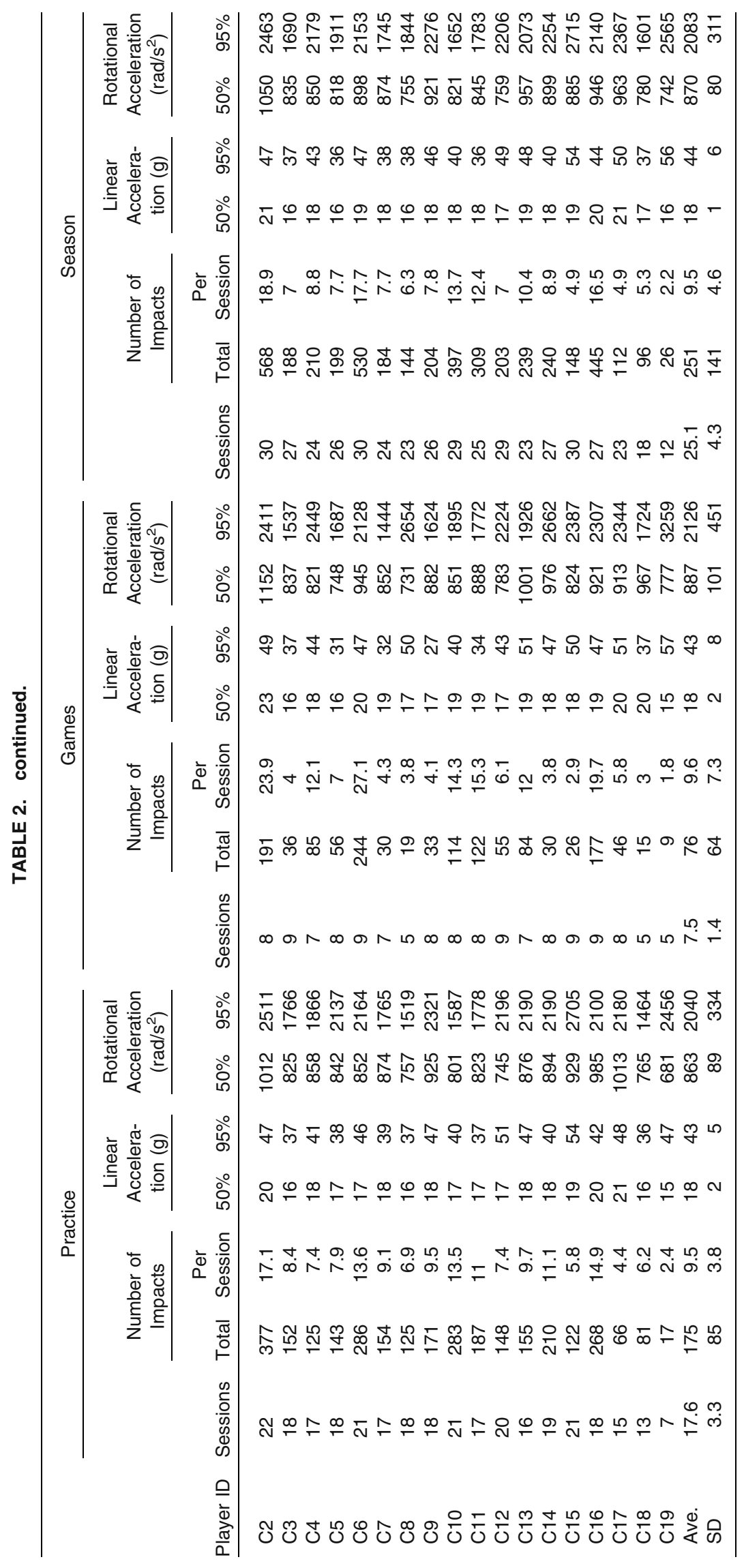




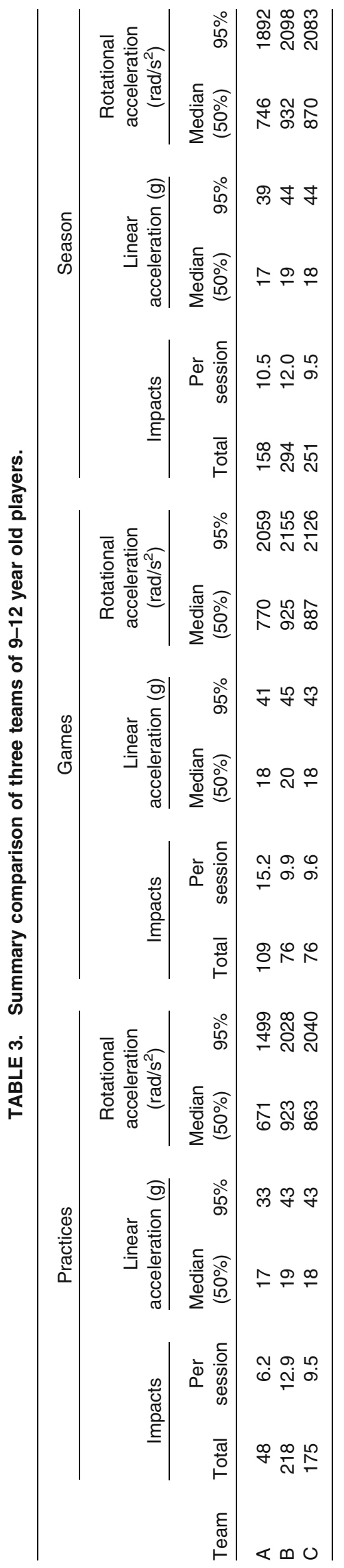

player had a median rotational acceleration value of $829 \pm 152 \mathrm{rad} / \mathrm{s}^{2}$ and a 95th percentile value of $1884 \pm 385 \mathrm{rad} / \mathrm{s}^{2}$. As with linear acceleration, the difference between game and practice 95 th percentile rotational acceleration $(p=0.0099)$ was significant. The average player sustained $154 \pm 113$ impacts in $14.4 \pm 5.2$ contact practices and $85 \pm 68$ impacts in $7.4 \pm 1.2$ games. On a per session basis, players experienced $9.7 \pm 4.9$ impacts per practice and $11.3 \pm 8.7$ impacts per game. While players experienced significantly more impacts in practices than games $(p=0.0011)$ throughout the season, the difference in the number of impacts per session for practices and games ( $p=0.9423)$ was not significant.

Substantial differences existed among the three teams in this study for both impact frequency and acceleration magnitude (Table 3). Players on team A accumulated fewer impacts in practices during the season $(p<0.0001)$ than those on teams B and $\mathrm{C}$, as well as fewer impacts on a per practice basis $(p<0.0097)$. Furthermore, team A players sustained appreciably lower magnitude accelerations than their team B and C counterparts (Fig. 3). For linear acceleration magnitude, the 95 th $(p<0.0001)$ percentile differences between team $\mathrm{A}$ and the other two was significant for practices. Likewise, the difference in rotational acceleration magnitudes between team $\mathrm{A}$ and teams $\mathrm{B}$ and $\mathrm{C}$ was significant for the median $(p<0.0001)$ and 95 th percentile $(p<0.002)$ values for practices. In games, impact frequency and acceleration magnitudes were not significantly different among the teams. Team A players sustained significantly fewer impacts throughout the season compared to team B players $(p=0.0045)$ due to practice differences. While team A players also sustained fewer impacts during the season than team $\mathrm{C}$ players, the difference was not significant $(p=0.0742)$.

Impacts to the front of the helmet were the most common, representing $41 \%$ of all impacts, followed by those to the back at $25 \%$ and side at $23 \%$ (Table 4 ). The least frequently impacted location was the top of the helmet, representing $11 \%$ of all impacts. Impacts to the top of the helmet resulted in the highest magnitude linear accelerations with a median value of $21 \mathrm{~g}$ and a 95 th percentile value of $46 \mathrm{~g}$. For rotational acceleration, impacts to the front had the highest values while those to the top had the lowest.

Among the three teams participating in this study, four instrumented players sustained concussions diagnosed by physicians: two on the pee wee team (B4 and B6) and one on each of the other two teams (A8 and C18). The impact associated with player A8's concussion was to the front of the helmet and had a linear acceleration of $58 \pm 9 \mathrm{~g}$ and rotational acceleration of $4548 \pm 1400 \mathrm{rad} / \mathrm{s}^{2}$. For player B4, the concussion was 

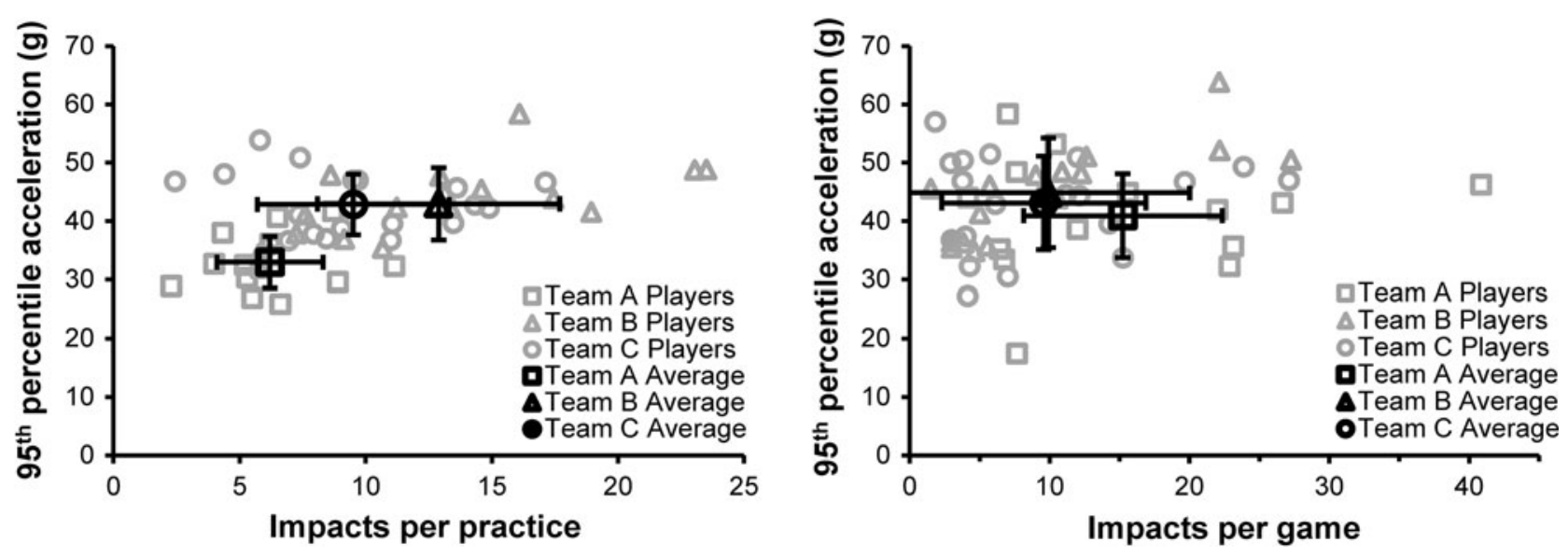

FIGURE 3. Player 95th percentile acceleration magnitude vs. number of impacts per session for practices (left) and games (right). Individual players are shown in gray while team averages are displayed in black with error bars showing standard deviation.

TABLE 4. Head impact frequency and magnitude by location for 9-12 year old players.

\begin{tabular}{|c|c|c|c|c|c|}
\hline \multirow[b]{2}{*}{ Location } & \multirow{2}{*}{$\begin{array}{l}\text { Percentage of } \\
\text { impacts (\%) }\end{array}$} & \multicolumn{2}{|c|}{$\begin{array}{l}\text { Linear accel- } \\
\text { eration }(\mathrm{g})\end{array}$} & \multicolumn{2}{|c|}{$\begin{array}{l}\text { Rotational } \\
\text { acceleration } \\
\left(\mathrm{rad} / \mathrm{s}^{2}\right)\end{array}$} \\
\hline & & 50th & 95th & 50th & 95th \\
\hline Front & 52 & 19 & 41 & 951 & 2049 \\
\hline Side & 19 & 16 & 34 & 810 & 1715 \\
\hline Rear & 18 & 18 & 41 & 790 & 2030 \\
\hline Top & 10 & 21 & 46 & 388 & 1040 \\
\hline
\end{tabular}

associated with an impact to the back of the helmet with linear and rotational acceleration magnitudes of $64 \pm 10 \mathrm{~g}$ and $2830 \pm 900 \mathrm{rad} / \mathrm{s}^{2}$. No impacts were recorded for $\mathrm{B} 6$ on the day of his concussion due to a battery failure in the sensor array. Player C18's concussion was linked to an impact to the side of the helmet with linear and rotational acceleration magnitudes of $26 \pm 4 \mathrm{~g}$ and $1552 \pm 500 \mathrm{rad} / \mathrm{s}^{2}$.

\section{DISCUSSION}

Previous studies have investigated the frequency and magnitude of head impacts in other tackle football populations, including youth (7-8 years), high school (14-18 years), and college (18-23 years) in the last decade (Table 5). ${ }^{5,11,25,27}$ Data from these studies show a trend of increasing acceleration magnitude and impact frequency with increasing level of play. Not surprisingly, the 9-12 year old players in this study were found to experience linear acceleration magnitudes between those found in 7-8 year old players and high school players. For rotational acceleration, the 95th percentile magnitude found in this study was less than that found previously in younger players. ${ }^{11}$
Rotational acceleration tends to correlate well with linear acceleration, though impact location can heavily influence the relationship. ${ }^{27}$ Players in this study experienced more impacts to the front of their helmets and fewer to the side than the 7-8 year old players studied by Daniel et al. ${ }^{11}$ In that study, impacts to the front of player's helmets were associated with lower rotational acceleration magnitudes, while those to the side were associated with higher magnitudes.

As with magnitude, the impact frequency reported in this study fell between those of 7-8 year old and high school athletes. In this study, the average player experienced 240 impacts throughout the season compared to 107 impacts per season for 7-8 year old players and 565 for high school players. ${ }^{3,5,11}$ This trend can be partially attributed to the number of sessions (practices and games) increasing as the level of play increases. The 7-8 year old team studied by Daniel et al. ${ }^{11}$ experienced impacts in 9.4 practices and 4.7 games for a total of 14.1 sessions. Players in this study participated in an average of 14.4 contact practices and 7.4 games, for a total of 21.8 sessions. Compared to the high school team studied by Broglio et al., ${ }^{3}$ the teams in this study participated in fewer practices and games in addition to experiencing fewer impacts per session. High school players experienced on average 15.9 impacts per session whereas the 9-12 year old players in this study experienced 10.6 impacts per session. The age related differences reported among these three age groups are most likely due to increased size, athleticism, and aggression in older players.

Players experienced slightly greater impact frequencies and acceleration magnitudes in games than in practice, similar to findings of high school and college football studies. ${ }^{4,7,9,29}$ For example, a group of high school players, experienced a mean linear acceleration magnitude of $23 \mathrm{~g}$ in practices and $25 \mathrm{~g}$ in games while 
TABLE 5. Comparison of head impact exposure across various levels of play..$^{3,5,11,25,27}$

\begin{tabular}{|c|c|c|c|c|c|}
\hline \multirow[b]{2}{*}{ Level of play } & \multirow[b]{2}{*}{ Number of impacts per season } & \multicolumn{2}{|c|}{ Linear acceleration (g) } & \multicolumn{2}{|c|}{$\begin{array}{l}\text { Rotational acceleration } \\
\left(\mathrm{rad} / \mathrm{s}^{2}\right)\end{array}$} \\
\hline & & Median $(50 \%)$ & $95 \%$ & Median (50\%) & $95 \%$ \\
\hline Youth (7-8 years) & 107 & 15 & 40 & 672 & 2347 \\
\hline Youth (9-12 years) & 240 & 18 & 43 & 856 & 2034 \\
\hline High school (14-18 years) & 565 & 21 & 56 & 903 & 2527 \\
\hline College (19-23 years) & 1000 & 18 & 63 & 981 & 2975 \\
\hline
\end{tabular}

the players in this study had a mean linear acceleration magnitude of $22 \mathrm{~g}$ in practices and $23 \mathrm{~g}$ in games. ${ }^{5}$ With regard to impact frequency, players in this study experienced a similar number of impacts per practice as per game. The rate of impact in practice was similar to the 9.2 impacts per practice that Broglio et al. ${ }^{5}$ reported for high school football players. However, the high school players sustained 24.5 impacts per game. These data suggest that high school players experience fewer impacts in practice than in games, while the 912 year old players in this study had roughly equal numbers of impacts per session for the two session types.

Substantial differences in impact frequency were observed between team A and the other two teams. For the entire season, players on team A experienced an average of $37-46 \%$ fewer impacts than players on teams $\mathrm{B}$ and $\mathrm{C}$, though only the difference between teams A and B was statistically significant. This difference is largely due to players on teams B and C participating in 2.1-2.3 times more contact practices than players on team A. The average number of games each player participated in was nearly the same for all three teams, and team A actually had the highest average number of impacts per game at 15.2. Team B and $C$ players averaged 9.9 and 9.6 impacts per game, respectively. Since team A had fewer players than the other two teams, their players may have had more playing time leading to more impacts per game, though other factors such as playing style or skill may have also played a role. For practices, team A players averaged just 6.2 impacts per session compared to 12.9 and 9.5 for teams B and C. Furthermore, players from teams $\mathrm{B}$ and $\mathrm{C}$ participated in twice as many practice sessions as those from team $\mathrm{A}$. As a result of the higher rate of impact in practices and greater number of practices, team B and C players experienced 219 and 175 impacts during practices, while team A players averaged 48 impacts.

Several factors may have played a role in reducing the head impact exposure observed in team A players relative to teams B and C in this study. First, Pop Warner mandated two rule changes for the 2012 football season that applied to all of their affiliates: (1) a mandatory minimum play rule, where coaches are required to give each player a certain amount of playing time, and (2) a limit on contact in practice, where no more than one-third of weekly practice time and no more than $40 \mathrm{~min}$ of a single session can involve contact drills. ${ }^{28}$ While no team in this study was affiliated with Pop Warner, the league in which team A competed enforced the same rule changes, whereas teams B and C had no such restrictions. Second, special teams plays, including kickoffs and punts, were live plays for teams B and C, similar to high school, college, and professional football. Alternatively, team A's special teams plays were controlled situations where no contact was allowed. Data from previous studies suggest that players on special teams are more susceptible to large magnitude head accelerations, which may lead to higher incidence of concussion on these plays. $^{2,18,21}$ Third, all three teams played approximately the same number of games during the season, but teams $\mathrm{B}$ and $\mathrm{C}$ played 11 and 12 week seasons while team A had a 9 week season. With more time between games, teams generally practice at a higher frequency and intensity. Fourth, player skill, athleticism, and maturity could have implications on the level of exposure. Even within teams, variability among players is apparent, with some players experiencing substantially more impacts than the team average. No significant differences were found in game acceleration magnitudes or impact frequency, suggesting practice differences were not due to player differences among teams. Instrumented players ranged from experiencing 72 to 585 head impacts. Fifth, coaching style has major influence on factors such as the types of drills used in practice and the plays called in games. These coaching variations would likely contribute to the differences in the head impact exposure that players experienced.

Two of the impacts (A8 and B4) associated with diagnosed concussions were substantially greater than the player's season 95th percentile linear acceleration magnitude. Furthermore, the acceleration magnitudes were consistent with concussive values reported in previous studies, albeit at the lower end of the range. ${ }^{16,25,27}$ For player A8, the impact was the third highest linear acceleration magnitude he experienced during the season and second highest magnitude 
resulting from an impact to the front of the helmet. The two highest magnitude impacts that this player experienced were similar in magnitude to the concussive impact. For player B4, the concussive impact was his highest magnitude impact to the back of the helmet for the season. This player also accumulated the third highest number of impacts during the season among all study participants. The third impact associated with a concussion (C18) was in the top $20 \%$ of linear acceleration magnitudes for that player throughout the season. Although the acceleration magnitude was relatively low for a concussion, it was the player's second highest magnitude resulting from an impact to the side of the helmet.

The data collected in this study may have applications towards improving the safety of youth football through rule changes, coach training, and equipment design. Prior to the 2012 season, many youth football organizations, including the league in which team A competed, modified rules, and provided coaches with practice guidelines to reduce head impacts in practice. The data collected in this study suggest that head impact exposure over the course of a season can be reduced significantly by limiting contact in practices to levels below those experienced in games. In addition to guiding future rules for youth football, this study can be used to aid designers in developing youth-specific football helmets that may be able to better reduce head accelerations due to head impacts for young football players. Impact location, frequency, and head acceleration magnitudes can be used to optimize helmet padding to maximize protection while keeping factors such as helmet size and mass to age appropriate levels.

A number of limitations should be noted about this study. First, the HIT system used for data collection is associated with some measurement error for linear and rotational acceleration. On average, the HIT system overestimates linear acceleration by $1 \%$ and rotational acceleration by $6 \%$ when compared to the Hybrid III headform. The correlation between the HIT system and Hybrid III measurements of head acceleration is $R^{2}=0.903$ for linear acceleration and $R^{2}=0.528$ for rotational acceleration. ${ }^{1}$ Individual data points have uncertainty values due to random error as well; however, the analysis presented here primarily examined distributions of data sets, rather than individual points. Uncertainty values that account for the random error are included with the three concussive data points presented. Second, this study followed three teams consisting of 9-12 year old players with a total of 50 players with large variations in head impact exposure among the different teams and players. Head impact exposure is likely dependent on other factors, in addition to age.
Real-time head impact kinematic data were collected from youth football players, age 9-12 years, during practice and game sessions for an entire season. The data show, on average, that players experienced greater head impact exposure, through more frequent and higher magnitude impacts, than 7-8 year old players, but less than that of high school players. Furthermore, players experienced similar levels of head impact exposure in practice and game sessions on a per-session basis. The vast majority of head impacts recorded in both games and practices were below acceleration magnitudes generally associated with concussions; though, some high magnitude impacts, similar to those seen among older players, did occur. The data presented in this study suggest that head impact exposure at the youth level may effectively be reduced by limiting contact in practices. Future studies are required to determine how rule modifications, coaching style, and other factors influence player impact exposure in practice. Furthermore, additional research is required to determine how reducing head impact exposure in practice affects concussion risk in youth football. Researcher should continue to collect head impact kinematic data in youth football across all age groups to establish the level of head impact exposure a typical player experiences, in a season and career, in order to improve player safety in youth football.

\section{ACKNOWLEDGMENTS}

The authors would like to thank the Childress Institute for Pediatric Trauma at Wake Forest Baptist Medical Center and the National Highway Traffic Safety Administration for providing support for this study as well as Elizabeth Lillie, Matt Bennett, Amanda Dunn, and the South Fork Panthers and Blacksburg youth football programs for their involvement.

\section{OPEN ACCESS}

This article is distributed under the terms of the Creative Commons Attribution License which permits any use, distribution, and reproduction in any medium, provided the original author(s) and the source are credited.

\section{REFERENCES}

${ }^{1}$ Beckwith, J. G., R. M. Greenwald, and J. J. Chu. Measuring head kinematics in football: correlation between the 
head impact telemetry system and Hybrid III headform. Ann. Biomed. Eng. 40(1):237-248, 2012.

${ }^{2}$ Boden, B. P., R. L. Tacchetti, R. C. Cantu, S. B. Knowles, and F. O. Mueller. Catastrophic head injuries in high school and college football players. Am. J. Sports Med. 35(7): 1075-1081, 2007.

${ }^{3}$ Broglio, S. P., B. Schnebel, J. J. Sosnoff, S. Shin, X. Fend, $\mathrm{X}$. He, and J. Zimmerman. Biomechanical properties of concussions in high school football. Med. Sci. Sports Exerc. 42(11):2064-2071, 2010.

${ }^{4}$ Broglio, S. P., J. J. Sosnoff, S. Shin, X. He, C. Alcaraz, and J. Zimmerman. Head impacts during high school football: a biomechanical assessment. J. Athl. Train. 44(4):342-349, 2009.

${ }^{5}$ Broglio, S. P., T. Surma, and J. A. Ashton-Miller. High school and collegiate football athlete concussions: a biomechanical review. Ann. Biomed. Eng. 40(1):37-46, 2012.

${ }^{6}$ Crisco, J. J., J. J. Chu, and R. M. Greenwald. An algorithm for estimating acceleration magnitude and impact location using multiple nonorthogonal single-axis accelerometers. J. Biomech. Eng. 126(6):849-854, 2004.

${ }^{7}$ Crisco, J. J., R. Fiore, J. G. Beckwith, J. J. Chu, P. G. Brolinson, S. Duma, T. W. McAllister, A. C. Duhaime, and R. M. Greenwald. Frequency and location of head impact exposures in individual collegiate football players. J. Athl. Train. 45(6):549-559, 2010.

${ }^{8}$ Crisco, J. J., and R. M. Greenwald. Let's get the head further out of the game: a proposal for reducing brain injuries in helmeted contact sports. Curr. Sports Med. Rep. 10(1):7-9, 2011.

${ }^{9}$ Crisco, J. J., B. J. Wilcox, J. G. Beckwith, J. J. Chu, A. C. Duhaime, S. Rowson, S. M. Duma, A. C. Maerlender, T. W. McAllister, and R. M. Greenwald. Head impact exposure in collegiate football players. J. Biomech. 44(15): 2673-2678, 2011.

${ }^{10}$ Crisco, J. J., B. J. Wilcox, J. T. Machan, T. W. McAllister, A. C. Duhaime, S. M. Duma, S. Rowson, J. G. Beckwith, J. J. Chu, and R. M. Greenwald. Magnitude of head impact exposures in individual collegiate football players. J. Appl. Biomech. 28(2):174-183, 2012.

${ }^{11}$ Daniel, R. W., S. Rowson, and S. M. Duma. Head impact exposure in youth football. Ann. Biomed. Eng. 40(4):976981, 2012.

${ }^{12}$ Duma, S. M., and S. Rowson. Past, present, and future of head injury research. Exerc. Sport Sci. Rev. 39(1):2-3, 2011.

${ }^{13}$ Funk, J. R., S. Rowson, R. W. Daniel, and S. M. Duma. Validation of concussion risk curves for collegiate football players derived from hits data. Ann. Biomed. Eng. 40(1):7989,2012

${ }^{14}$ Gilchrist, J., K. Thomas, L. Xu, L. McGuire, and V. Coronado. Nonfatal traumatic brain injuries related to sports and recreation activities among persons aged $\leq 19$ years-United States, 2001-2009. Morb. Mortal. Wkly Rep. 60(39):1337-1342, 2011.

${ }^{15}$ Greenwald, R. M., J. T. Gwin, J. J. Chu, and J. J. Crisco. Head impact severity measures for evaluating mild traumatic brain injury risk exposure. Neurosurgery 62(4):789798; discussion 798, 2008.

${ }^{16}$ Guskiewicz, K. M., and J. P. Mihalik. Biomechanics of sport concussion: quest for the elusive injury threshold. Exerc. Sport Sci. Rev. 39(1):4-11, 2011.

${ }^{17}$ Guskiewicz, K. M., J. P. Mihalik, V. Shankar, S. W. Marshall, D. H. Crowell, S. M. Oliaro, M. F. Ciocca, and D. N. Hooker. Measurement of head impacts in collegiate football players: relationship between head impact biomechanics and acute clinical outcome after concussion. Neurosurgery 61(6):1244-1253, 2007.

${ }^{18}$ Guskiewicz, K. M., N. L. Weaver, D. A. Padua, and W. E. Garrett, Jr. Epidemiology of concussion in collegiate and high school football players. Am. J. Sports Med. 28(5):643650, 2000.

${ }^{19}$ Langlois, J. A., W. Rutland-Brown, and M. M. Wald. The epidemiology and impact of traumatic brain injury: a brief overview. J. Head Trauma Rehabil. 21(5):375-378, 2006.

${ }^{20}$ Manoogian, S., D. McNeely, S. Duma, G. Brolinson, and R. Greenwald. Head acceleration is less than 10 percent of helmet acceleration in football impacts. Biomed. Sci. Instrum. 42:383-388, 2006.

${ }^{21}$ Pellman, E. J., J. W. Powell, D. C. Viano, I. R. Casson, A. M. Tucker, H. Feuer, M. Lovell, J. F. Waeckerle, and D. W. Robertson. Concussion in professional football: epidemiological features of game injuries and review of the literature - part 3. Neurosurgery 54(1):81-94; discussion 94-96, 2004.

${ }^{22}$ Pellman, E. J., D. C. Viano, A. M. Tucker, and I. R. Casson. Concussion in professional football: location and direction of helmet impacts - part 2. Neurosurgery 53(6): 1328-1340; discussion 1340-1341, 2003.

${ }^{23}$ Pellman, E. J., D. C. Viano, A. M. Tucker, I. R. Casson, and J. F. Waeckerle. Concussion in professional football: reconstruction of game impacts and injuries. Neurosurgery 53(4):799-812; discussion 814, 2003.

${ }^{24}$ Powell, J. W., and K. D. Barber-Foss. Traumatic brain injury in high school athletes. JAMA 282(10):958-963, 1999.

${ }^{25}$ Rowson, S., and S. M. Duma. Development of the star evaluation system for football helmets: integrating player head impact exposure and risk of concussion. Ann. Biomed. Eng. 39(8):2130-2140, 2011.

${ }^{26}$ Rowson, S., and S. M. Duma. Brain injury prediction: assessing the combined probability of concussion using linear and rotational head acceleration. Ann. Biomed. Eng. 41(5):873-882, 2013.

${ }^{27}$ Rowson, S., S. M. Duma, J. G. Beckwith, J. J. Chu, R. M. Greenwald, J. J. Crisco, P. G. Brolinson, A. C. Duhaime, T. W. McAllister, and A. C. Maerlender. Rotational head kinematics in football impacts: an injury risk function for concussion. Ann. Biomed. Eng. 40(1):1-13, 2012.

${ }^{28}$ Rules changes regarding practice $\&$ concussion prevention. http://www.popwarner.com/About_Us/Pop_Warner_News/ Rule_Changes_Regarding_Practice__Concussion_Prevention_ s1_p3977.htm, 2012.

${ }^{29}$ Schnebel, B., J. T. Gwin, S. Anderson, and R. Gatlin. In vivo study of head impacts in football: a comparison of National Collegiate Athletic Association Division I versus high school impacts. Neurosurgery 60(3):490-495; discussion 495-496, 2007.

${ }^{30}$ Stern, R. A., D. O. Riley, D. H. Daneshvar, C. J. Nowinski, R. C. Cantu, and A. C. McKee. Long-term consequences of repetitive brain trauma: chronic traumatic encephalopathy. $P M \& R$ 3(10):S460-S467, 2011.

${ }^{31}$ Viano, D. C., and D. Halstead. Change in size and impact performance of football helmets from the 1970s to 2010. Ann. Biomed. Eng. 40(1):175-184, 2012.

${ }^{32}$ Viano, D. C., C. Withnall, and D. Halstead. Impact performance of modern football helmets. Ann. Biomed. Eng. 40(1):160-174, 2012. 
${ }^{33}$ Viano, D. C., C. Withnall, and M. Wonnacott. Effect of mouthguards on head responses and mandible forces in football helmet impacts. Ann. Biomed. Eng. 40(1):47-69, 2012.
${ }^{34}$ Viano, D. C., C. Withnall, and M. Wonnacott. Football helmet drop tests on different fields using an instrumented Hybrid III head. Ann. Biomed. Eng. 40(1):97-105, 2012. 